\title{
FRICTION STIR PROCESSING OF CAST ALLOY 718
}

\author{
Bharat K. Jasthi ${ }^{1}$, Edward Chen ${ }^{2}$, Brahmanandam Kaligotla ${ }^{1}$, Todd Curtis ${ }^{3}$, Michael West ${ }^{1}$, Christian Widener ${ }^{1,3}$ \\ ${ }^{1}$ Department of Materials and Metallurgical Engineering; ${ }^{3}$ Arbegast Advanced Materials and Processing Laboratory; \\ South Dakota School of Mines and Technology; 501 East Saint Joseph St; Rapid City, SD 57701, USA \\ ${ }^{2}$ Transition45 Technologies, Inc; 1739 North Case Street; Orange, CA 92865, USA
}

Keywords: Friction Stir Processing, Alloy 718, Castings

\begin{abstract}
The primary objective of this work is to investigate the effect of Friction Stir Processing (FSP) on the microstructure and mechanical properties of Alloy 718 castings. Alloy 718 is often used in the cast form given the cost-effectiveness of this manufacturing approach for fabricating complex shapes near-net. The intense plastic deformation during the FSP process created a refined, recrystallized, equiaxed, and fine-grained microstructure while eliminating casting defects. Mechanical properties such as tensile, microhardness, and fatigue crack growth rates of the processed Alloy 718 were measured and compared to that of the parent material. FSP resulted in refined microstructure along with significant improvement in the tensile properties when compared to the parent material. Fatigue crack growth rate resistance for the processed material was found to be comparable with that of the parent material. The effects of post-FSP heat treatment cycles on the microstructure and mechanical properties were also analyzed and discussed.
\end{abstract}

\section{Introduction}

Alloy 718 is a nickel-based superalloy that has an excellent combination of properties such as corrosion resistance, strength, and toughness up to $650{ }^{\circ} \mathrm{C}$ [1]. As a result, it is extensively used in aircraft and industrial gas turbines for high temperature structures such as combuster cases and turbine disks as well as in rocket engines for turbopump components subjected to cryogenic and oxidizing conditions. Alloy 718 is often used in the cast form given the cost-effectiveness of this manufacturing approach for fabricating complex shapes near-net [2]. However, the use of castings often requires casting factors since properties such as durability and damage tolerance may be limited due to the presence of defects such as microfissures introduced during the fabrication process (e.g., from weld repairs). The microfissures that are introduced during the fusion welding process can lead to microcracks that subsequently grow when the component is subjected to stresses during use. The potential presence and growth of these microfissures are a limiting factor in the use of cast 718 for rocket engines (or gas turbines), and a casting factor is often needed leading to the overdesign of the part. Hence friction stir processing is of high interest for microstructural modification and also for eliminating the fusion weld defects. In recent years, many studies have reported the effectiveness of FSP for modifying and refining cast microstructures [3-12].

FSP is an innovative solid state microstructural modification technique, adapted from the concepts of friction stir welding (FSW) [13-14]. A schematic of the FSW process is shown in Figure 1. A rotating non-consumable pin tool is inserted in a work piece for localized microstructural modification to obtain specific properties of interest. The underlying principle is the conversion to thermal energy the mechanical energy of a rotating, non-consumable pin tool plunged into the surface of the work piece. During this process, heat is generated within the material from 1) friction between the pin tool and work piece and 2) severe plastic deformation of the material being processed. The intense plastic deformation in this process creates a fully recrystallized, equiaxed, and fine grained microstructure in the processed region. Since FSP is a solid state processing technique, most issues associated with fusion welding techniques such as the solidification cracking, grain boundary liquation cracking and strain age cracking can be avoided.

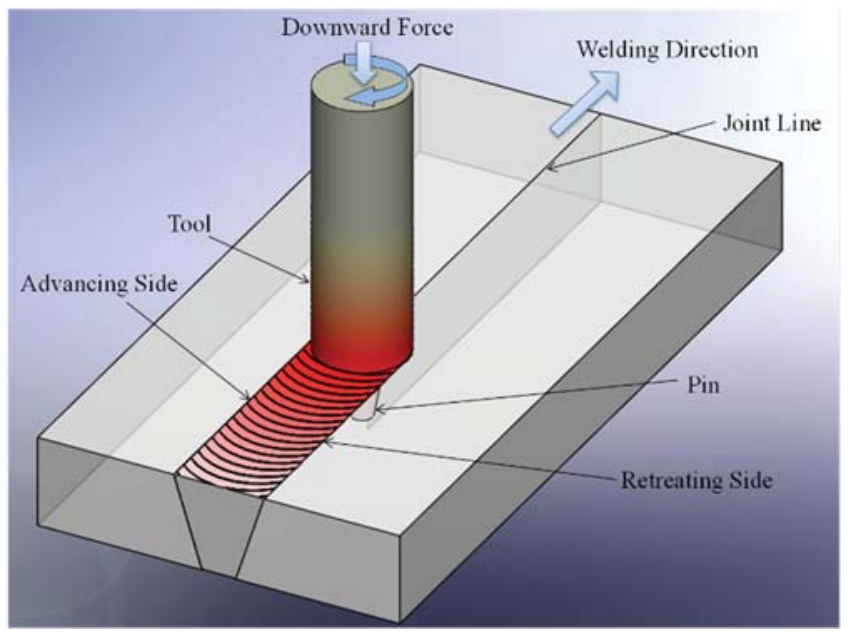

Figure 1. Schematic of a typical butt joint being created by friction stir welding.

Therefore, the purpose of this investigation was to determine the effect of friction stir processing on the microstructure and mechanical properties of cast Alloy 718 plates. Tensile properties, microhardness measurements along with fatigue crack growth rates were measured and compared with the parent material. The effects of post-FSP aging on the above mentioned mechanical properties were also analyzed and discussed.

\section{Experimental}

All the cast Alloy 718 plates used in this investigation were vacuum melted and processed in a manner consistent with AMS5383E [15] through to the completion of hot isostatic pressing (HIP) and subsequent non-destructive inspection. Material in this condition will be referred to as the "cast" material in this work. Hightemperature pin tools made of polycrystalline cubic boron nitride (PCBN) with a convex shoulder step spiral (CS4) design were used to process $5 \mathrm{~mm}$ thick cast Alloy 718 plates. 
All of the processing was performed using a multi-axis FSW system equipped with a water-cooled, high-temperature pin tool adapter (Figure 2). A radio-frequency telemetry system that was attached to the head allowed monitoring of the friction stir weld temperature immediately above the pin tool shoulder. The pitch and roll axis of the FSW head was isolated using pitch and roll isolators to minimize potential damage to the ceramic PCBN pin tools. The tools and cast Alloy 718 plates were shielded with argon gas during processing to prevent oxidation on the surface.

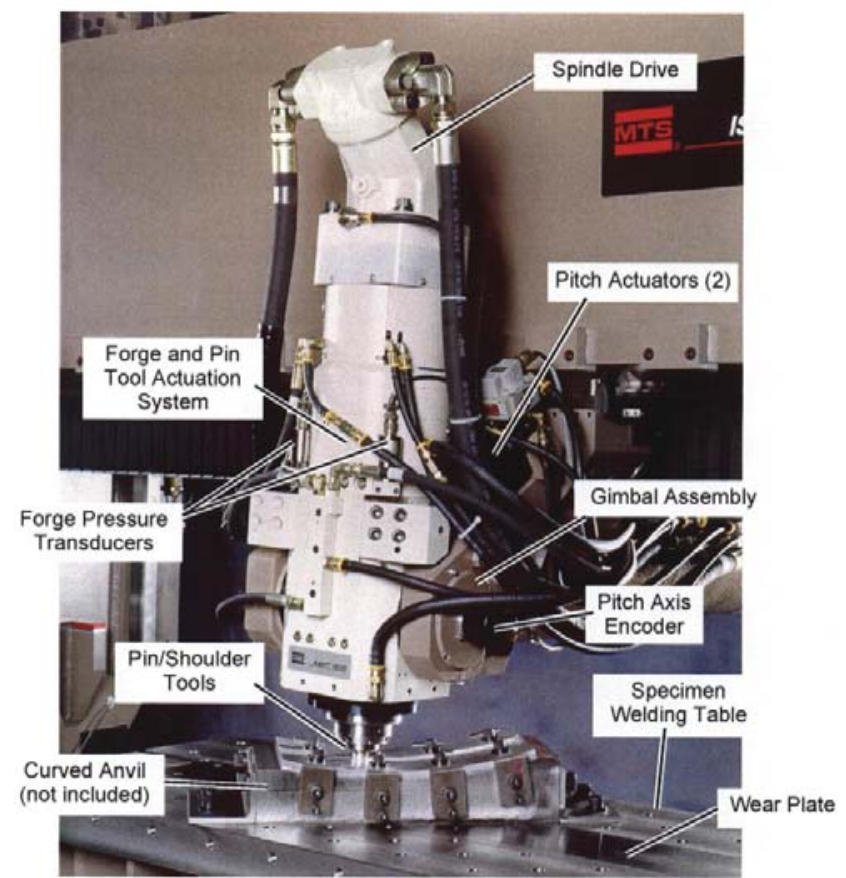

Figure 2. Multi-axis FSW head at South Dakota School of Mines and Technology.

FSP trials were made in position control mode at a zero degree tilt angle with the rotational speed ranging from 175 to $400 \mathrm{rev}^{\bullet} \mathrm{min}^{-1}$ and at a travel speed of $12.7 \mathrm{~mm} \cdot \mathrm{min}^{-1}$. After the plates were processed, they were sectioned perpendicular to the welding direction and prepared for metallographic examination using standard metallographic polishing procedures. The polished specimens were electrolytically etched with $5 \%$ oxalic acid at $1 \mathrm{~V}$ for few seconds. The specimens were examined using a metallurgical microscope. Based on the results from the process development trials, the optimum FSP parameters $\left(200 \mathrm{rev}^{\bullet} \mathrm{min}^{-1}\right.$ and $12.7 \mathrm{~mm} \cdot \mathrm{min}^{-1}$ ) which resulted in defect free FSP passes were selected and used to prepare the test panels for subsequent microstructural examination and mechanical testing.

To prepare these test panels, half of the plate was processed along the centerline from the top surface, the plate was turned over, and the other half of the plate was processed from the other surface, resulting in a double sided full penetration weld. Pictures of the FSP setup showing the PCBN pin tool and processed region are shown in Figure 3a. Each FSP pass was approximately $280 \mathrm{~mm}$ long on either side of the plate as shown in Figure 3b. Cast and friction stir processed plates were given heat treatment (HT) cycles as per AMS5383E specification and the details of the heat treatment cycles are given in Table I.
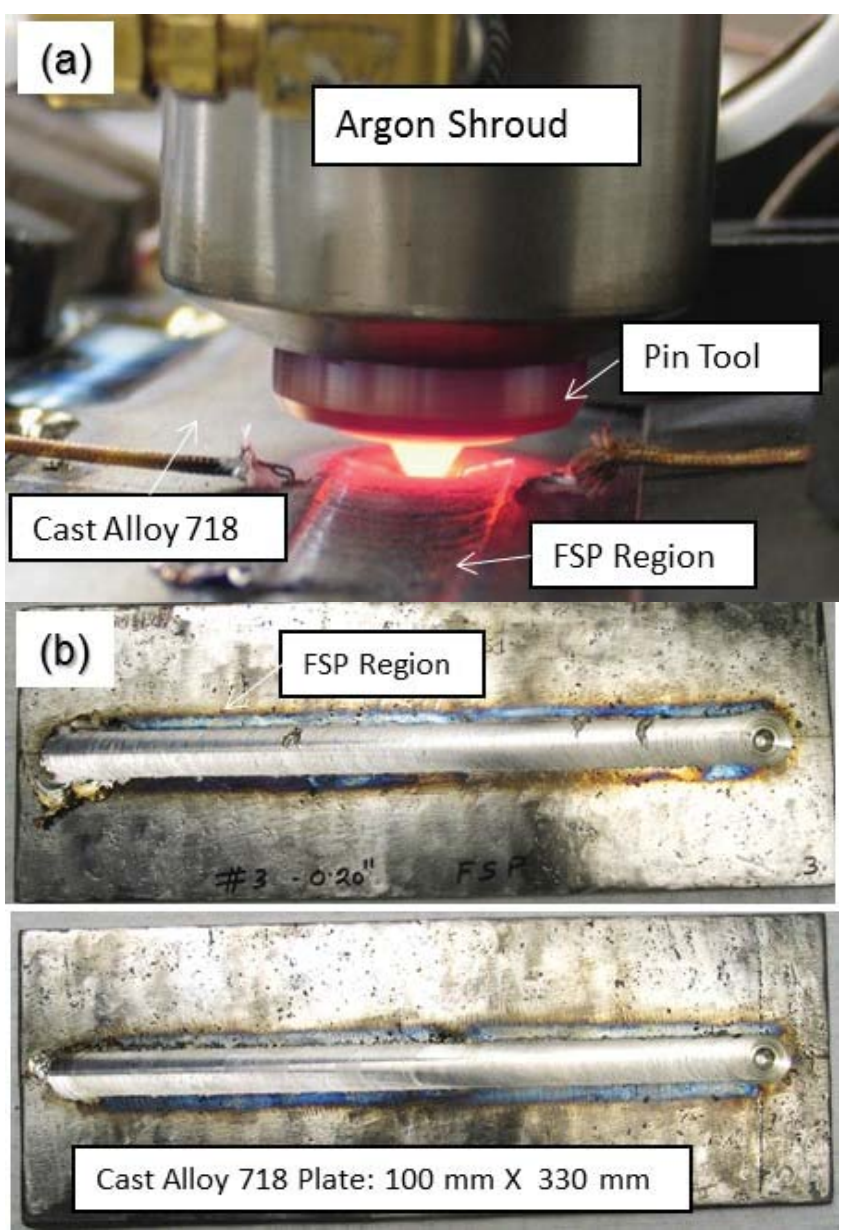

Figure 3. Friction stir processing showing: (a) Cast Alloy 718 and PCBN Pin tool; (b) resulted double-sided FSP pass at the center of the plate.

Table I. Heat Treatment Cycles Performed on Cast and Processed Specimens.

Homogenization

Solution Treatment

$1093^{\circ} \mathrm{C}$ for 2 hours, and forced air cooling. $954^{\circ} \mathrm{C}$ for 1 hour, and forced air cooling.

Precipitation Treatment $\quad 718^{\circ} \mathrm{C}$ for 8 hours, furnace cool to $621^{\circ} \mathrm{C}$, and $621^{\circ} \mathrm{C}$ for 8 hours, air cooling.

Tensile specimens were extracted in both transverse and longitudinal (all FSP) directions and tested as per ASTM E 8 standard. Compact tension specimens were prepared for fatigue crack growth rate measurements and tested in accordance with ASTM E 647-05 standard. The processed specimens had the notch and fatigue pre-crack oriented along the centerline of the processed region in the longitudinal direction, and opposite to the direction of weld travel.

Vickers microhardness measurements were made across the weld nugget at a distance of $2.0 \mathrm{~mm}$ from the top of the weld and at a horizontal spacing of $0.25 \mathrm{~mm}$ across the polished metallographic weld cross sections. The measurements were made at a load of $1 \mathrm{~kg}$ 
and a loading time of $20 \mathrm{~s}$ in accordance with ASTM E 92-82. Scanning electron microscopy (SEM) with energy-dispersive x-ray spectroscopy (EDX) was performed to characterize the microstructures and also to examine the fracture surfaces. FSP over the multi-pass tungsten inert gas (TIG) weld was also performed with the objective of simulating a TIG weld repair containing defects such as a cracks and microfissures.

\section{Results and Discussion}

Successful friction stir processing was performed in a forge control mode at $200 \mathrm{rev} \bullet \mathrm{min}^{-1}$ and $12.7 \mathrm{~mm} \bullet \mathrm{min}^{-1}$ and $42.2 \mathrm{kN}$ forge force. The macrograph of the double side friction stir processed material is shown in Figure 4. The cross section showed complete consolidation and no worm hole defects were identified in the processed region.

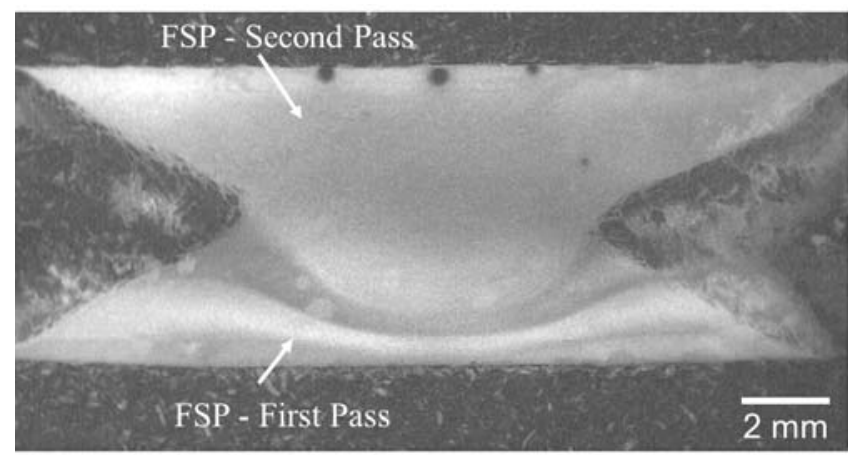

Figure 4. Macrograph showing the processed region of double-side friction stir processed Alloy 718.

The microstructures of the Cast and processed specimens were characterized using optical and SEM microscopy as shown in Figure 5. Microstructural examination of the Cast material revealed duplex grain structure with a large variation in grain size (average grain size $>100 \mu \mathrm{m}$ ) within the plate. Segregation of alloying elements and second phase particles was also observed at the grain boundaries as shown in Figure 5a. The processed region showed a completely refined and homogenized microstructure as shown in Figure 5b. The intense plastic deformation during the FSP process created a refined, recrystallized, equiaxed, and finegrained $(\sim 2 \mu \mathrm{m})$ microstructure while eliminating casting defects.

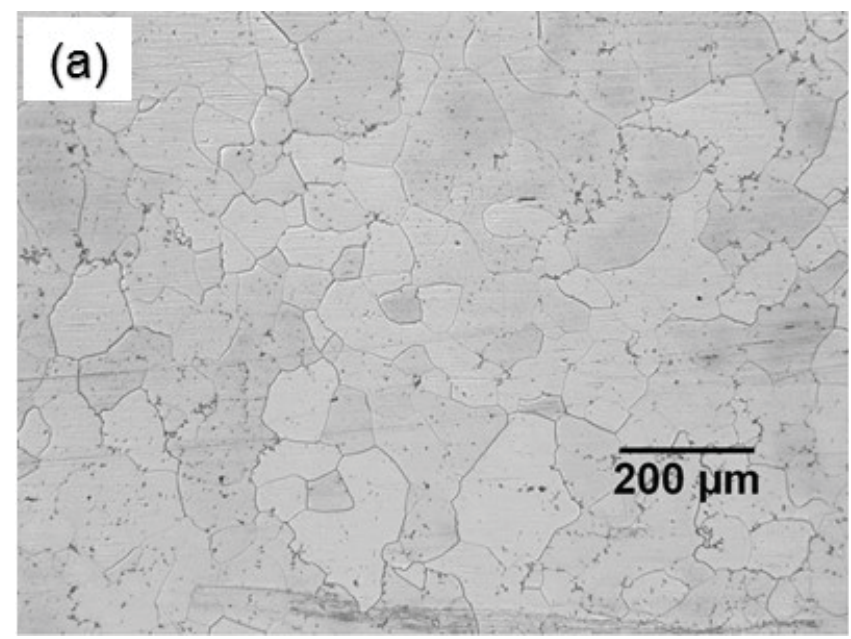

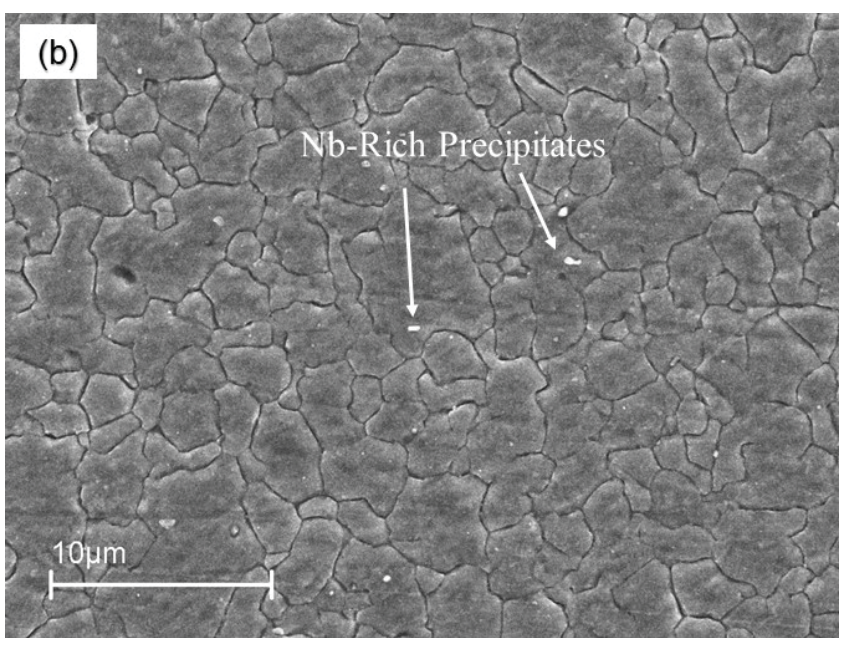

Figure 5. Micrographs of Alloy 718 showing: (a) Cast; and (b) friction stir processed.

Niobium-rich precipitates were identified in both the Cast and processed material. The size of the $\mathrm{Nb}$ precipitates in the Cast material (as shown in Figure 6) are relatively coarse when compared with the processed material (Figure 5b). The high strain rate conditions along with the processing temperatures could have broken the coarse $\mathrm{Nb}$ particles into smaller fractions during FSP process. Furthermore, the volume fraction of these precipitates in the Cast material appears to be significantly higher when compared with the processed material. It is possible that few of the precipitates may have dissolved into the matrix during the FSP process. $\mathrm{Nb}$ plays a vital role providing both solid solution strengthening and precipitation hardening in Alloy 718 . Maximizing the $\mathrm{Nb}$ concentration in solution maximizes strengthening during subsequent thermal aging. The decrease in $\mathrm{Nb}$ precipitates in the processed region might also eliminate the need for high-temperature, long-time, homogenization treatment cycles.

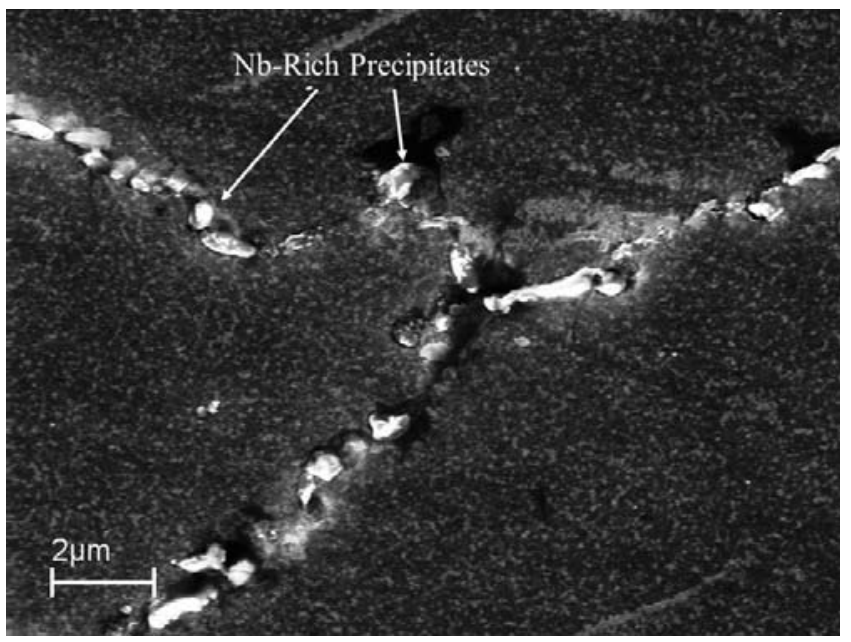

Figure 6: SEM micrograph of Cast Alloy 718 showing coarse $\mathrm{Nb}$ -rich precipitates decorating the grain boundaries.

Metallurgical examination after the full heat treat (HT) cycle on the FSP specimens showed grain growth from an average grain size of $2 \mu \mathrm{m}$ in the FSP condition to about $22 \mu \mathrm{m}$ in the FSP + HT 
condition. Even though there is an increase in the grain size after the heat treat cycle, but the grains are still finer when compared with grain size of the Cast material which is $\sim 100 \mu \mathrm{m}$.

Microhardness profiles taken across the weld nugget in various heat treated conditions are shown in Figure 7. The Cast plates had an average hardness of 400 Vickers (HVN). In the Cast + FSP condition, the nugget and heat affected zone (HAZ) regions show the characteristic "W" shape hardness curve with softening to a 250 $\mathrm{HVN}$ in the HAZ and $330 \mathrm{HVN}$ in the nugget region. After heat treatment, the Cast + HT specimen had an average hardness of 440 HVN while the Cast + FSP + HT (no homogenization cycle) had an increase in average hardness to about $460 \mathrm{HVN}$. When the full heat treat cycle (homogenization, solution treatment and aging) is applied to the FSP material, the average hardness further increased to $480 \mathrm{HVN}$.

The parent metal outside the nugget and HAZ approaches the Cast + HT hardness levels. The result of these hardness measurements show that the FSP nugget and HAZ when heat treated without the homogenization heat treat cycle have a higher hardness than the Cast + full HT. The full homogenization cycle further increases the strength of the FSP and HAZ regions.

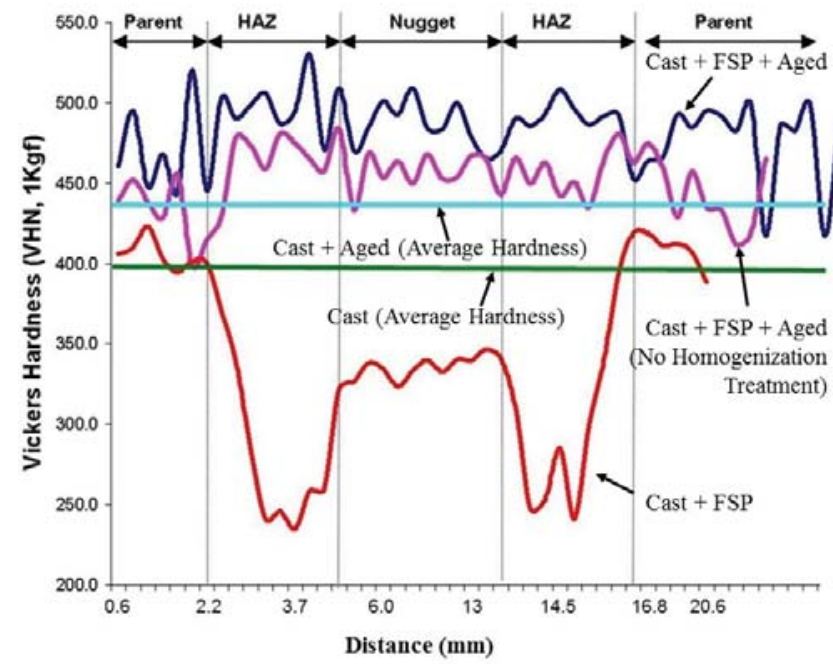

Figure 7: Microhardness profiles across the weld nugget as a function of heat treatment.

Transverse and longitudinal (all-FSP) tensile tests were conducted on all Cast, FSP, and heat treated conditions. The results are tabulated in Table II. All transverse tensile specimens fractured in lower-strength HAZ or in the parent material at locations where defects (e.g., dross inclusions) were present. Since the specimens failed in the locations where casting defects are present, a definitive effect of FSP on transverse tensile strength could not be determined. However, the longitudinal all-FSP specimens showed significant improvements in tensile properties in the Cast + FSP and Cast + FSP + HT specimens. The tensile properties of the AMS 5383 specification showing the minimums for the Investment Castings were included in the Table II for comparison. The increase in tensile strengths and \% elongation for the processed materials can be attributed to refined, recrystallized and fine grained microstructure formed during the FSP process.
Table II: Tensile Properties of Friction Stir Processed Alloy 718

\begin{tabular}{llll}
\hline Material & YS, MPa & $\begin{array}{l}\text { UTS, } \\
\text { MPa }\end{array}$ & $\begin{array}{l}\text { Elongation, } \\
\text { \% }\end{array}$ \\
\hline Cast & $751 \pm 124$ & $827 \pm 172$ & $3 \pm 1$ \\
Cast + HT & $951 \pm 158$ & $985 \pm 200$ & $4 \pm 1$ \\
Cast + FSP (transverse) & $572 \pm 48$ & $758 \pm 172$ & $7 \pm 7$ \\
$\begin{array}{l}\text { Cast + FSP + HT } \\
\text { (transverse) }\end{array}$ & $737 \pm 213$ & $779 \pm 179$ & $4 \pm 1$ \\
$\begin{array}{l}\text { All FSP (Longitudinal) } \\
\text { Al FSP + HT }\end{array}$ & 758 & 1068 & 24 \\
$\begin{array}{l}\text { (longitudinal) } \\
\text { AMS 5383 Min }\end{array}$ & 1213 & 1406 & 11 \\
$\begin{array}{l}\text { Investment Cast- } \\
\begin{array}{l}\text { Integrally cast and } \\
\text { specimens machined from } \\
\text { castings) }\end{array}\end{array}$ & 723 & & \\
\hline
\end{tabular}

SEM analysis showed a distinct difference in fracture mode between the Cast + HT, and the Cast + FSP + HT (all-FSP longitudinal) tensile fracture surfaces as shown in Figure 8.
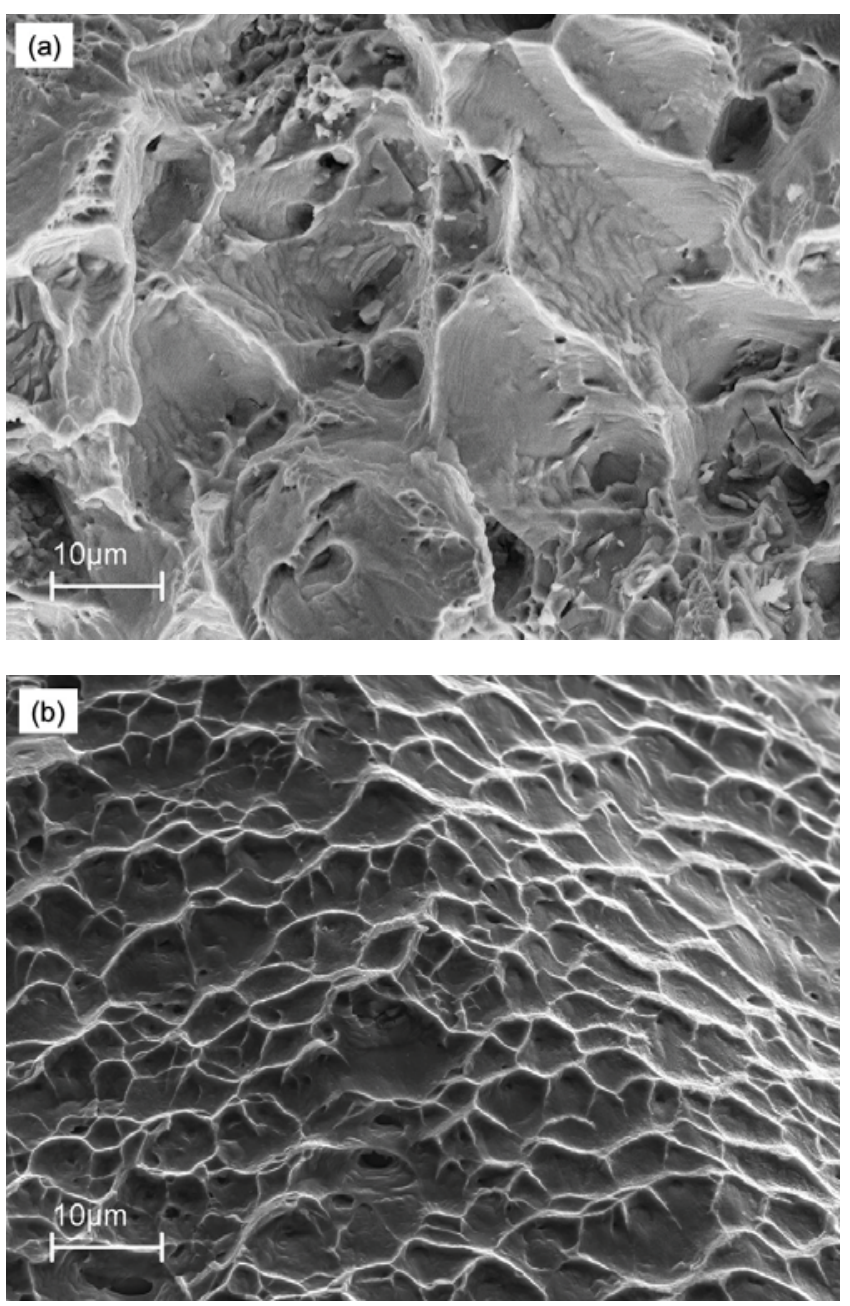

Figure 8: SEM analysis of tensile fracture surfaces: (a) Cast + HT; and (b) Cast +FSP + HT.

For the Cast + HT specimen (Figure 8a), a blocky, quasi-cleavage fracture surface was seen along with the presence of inclusions or 
large second phase particles. The fracture surface of the all-FSP specimen (Figure 8b) shows ductile microvoid coalescence (indicating a ductile failure) with little presence of dross inclusions or large second-phase particles.

Crack length progression as a function of fatigue cycles was tracked in compact tension specimens. The results are shown in Figure 9a. Here, crack growth for the processed material appears comparable with that for the parent material in the final heat treated condition. The crack growth rate $(\mathrm{da} / \mathrm{dN})$ as a function of cyclic stress intensity factor $(\Delta K)$ is plotted in Figure $9 \mathrm{~b}$. The crack propagation rates observed between the parent and processed material in the heat treated condition appear comparable in terms of overall slope $\mathrm{m}$. However, there does appear to be more scatter in the growth rates for the processed material. Furthermore, the threshold value for the processed material appears to be higher.
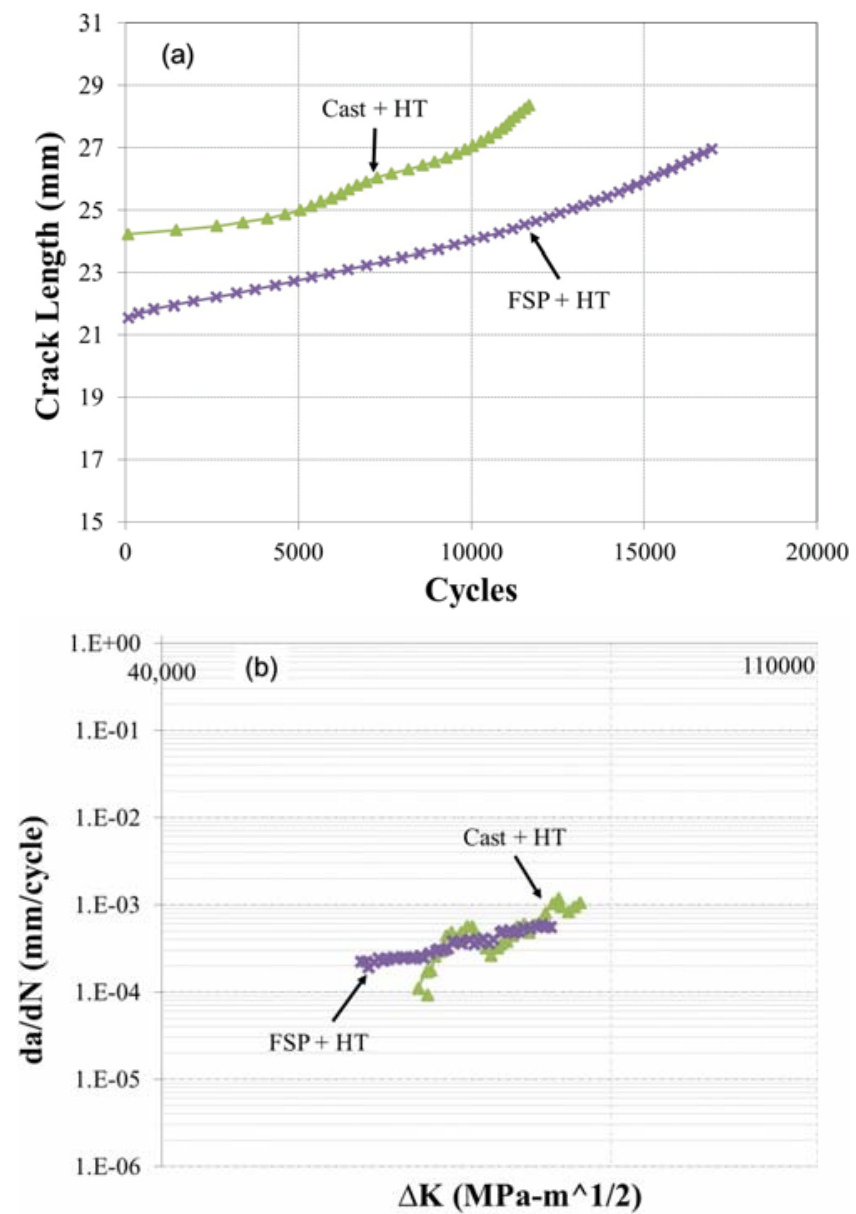

Figure 9: Comparison of fatigue crack growth resistance between parent and processed material in the heat treated condition as measured from compact tension specimens: (a) crack length vs. number of cycles; and (b) crack growth rate da/dN vs. cyclic stress intensity factor $\Delta K$.

Figure 10 shows a multi-pass weld nugget with a dendritic grain formation. Porosity was noted within the TIG weld in addition to interpass lack of fusion (LOF) and cracking. Entrapped dross was also observed in the weld, and believed to have originated from the as-received casting. After FSP, the dendritic structure is dynamically recrystallized within the nugget to a fine grain size and the interpass LOF was eliminated as shown in Figure 11.
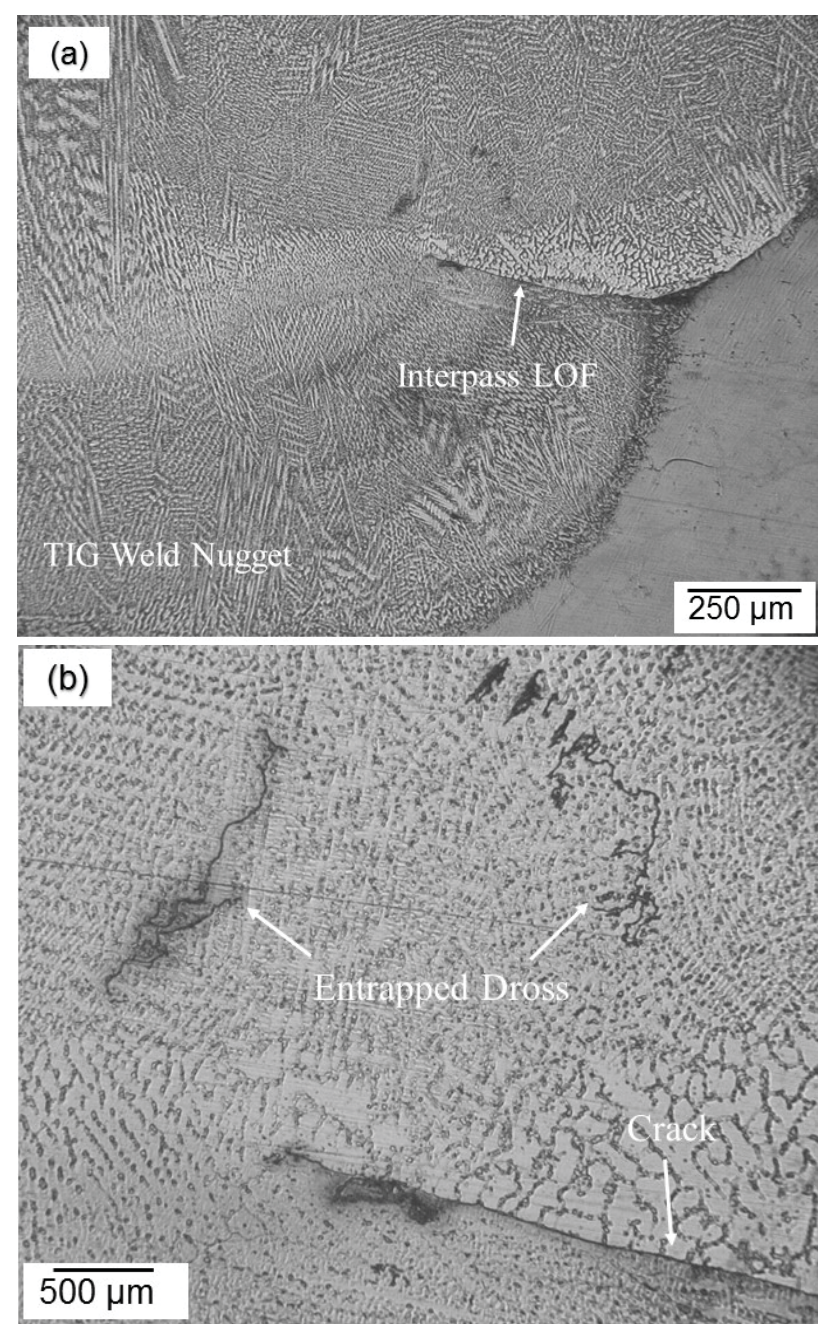

Figure 10: Simulated multi-pass TIG weld in Cast Alloy 718 showing fusion weld defects.

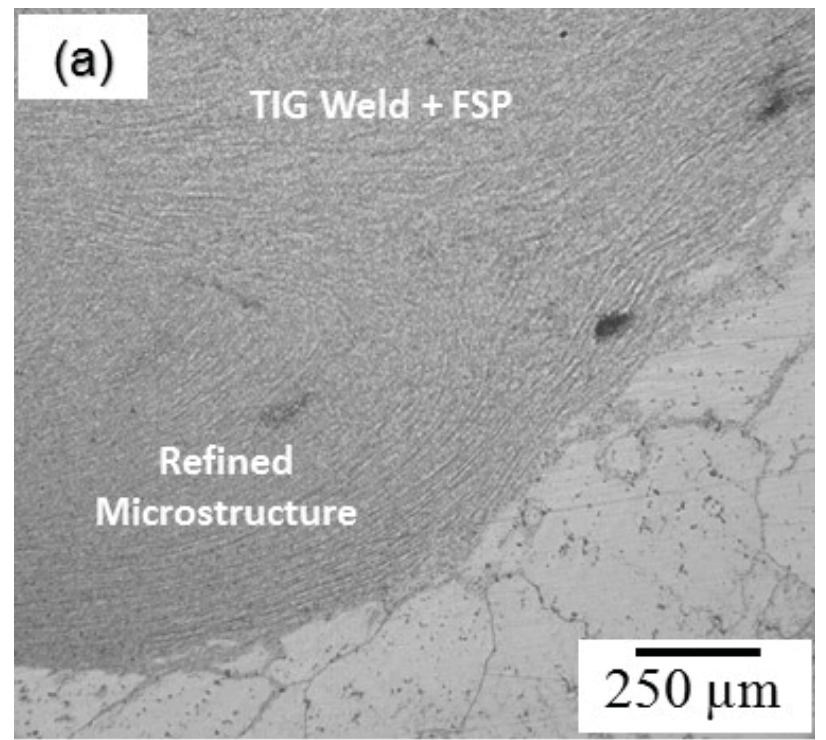




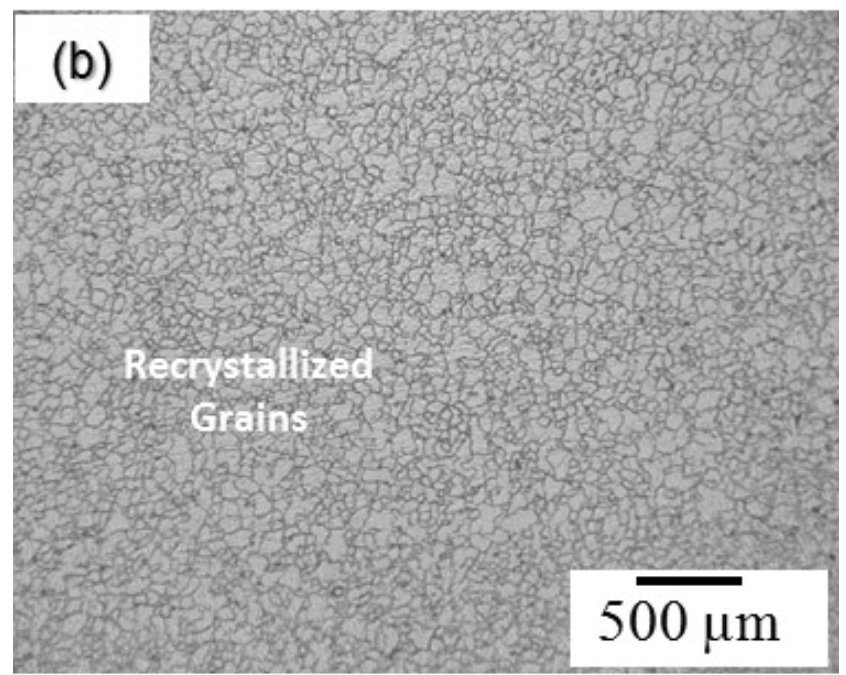

Figure 11: Simulated multi-pass TIG Repair in Cast Alloy 718 plate after FSP showing fine grain structure in the nugget region and elimination of the TIG weld defects.

Significant wear and degradation of the PCBN pin tool was noted during the FSP development trials. This was especially apparent in the higher rotation speed $\left(\mathrm{rev} \cdot \mathrm{min}^{-1}\right)$ trials, which are associated with higher temperatures. After the process development trials, PCBN pin tools showed wear in the scroll shoulder region as shown in Figure 12. Once the lower RPM optimized processing parameters were determined, the pin tools produced approximately $1000 \mathrm{~mm}$ of test panel FSP. During the parameter development trials, PCBN pin tools also showed the pin tip fracture from the shoulder as shown in Figure 12. This suggests that an increase in the diameter of the pin tip region may be necessary to resist fracture at this location. Rotation speeds should be kept low and sufficient cover gas should be provided to minimize oxidation and prevent wear of the PCBN pin tools. The processing parameter selection strongly affects the PCBN pin tool life: lower temperatures encountered with slower rotations speeds increase tool life. Alternate pin tools such as the Tungsten based tools (W-Re, and W-Re-HfC) should be explored in order to achieve improved tool life in nickel based alloys.
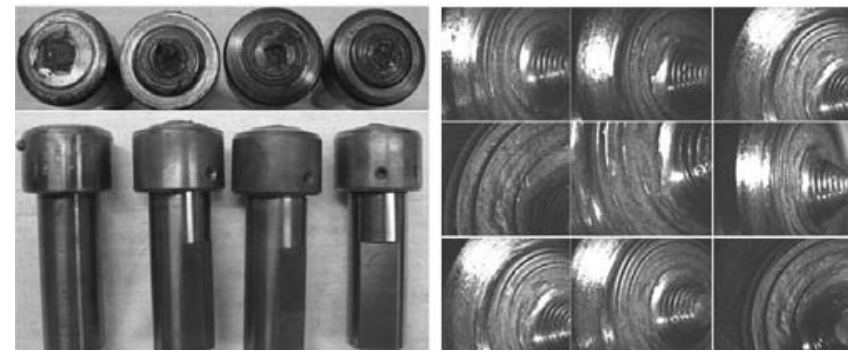

Figure 12: Broken PCBN pin tools (left) and wear on scroll shoulder feature (right).

\section{Conclusions}

Friction stir processing was successfully applied to cast Alloy 718 to modify the microstructure-properties of the parent material. The FSP nugget has an extremely fine grained recrystallized structure with an order of magnitude reduction in grain size over the original Cast material. FSP was found to increase the strength and response to heat treatment cycles, although some degree of grain growth occurs within the nugget region. This resultant grain size is smaller than the original Cast plate material. Significant improvement in the tensile strength and percent elongation observed for the FSP material when compared to the cast material. Fatigue crack growth rate resistance for the FSP material appears comparable to that of the parent material; although, more scatter was observed. TIG weld repair with FSP eliminated the dendritic microstructure and other fusion welding defects.

\section{Acknowledgements}

This work was supported by the National Aeronautics and Space Administration under Contract No. NNM07AA61C (Mr. F. Zimmerman, Program Manager). The authors also acknowledge the guidance of Dr. C. C. Bampton, formerly with Pratt \& Whitney Rocketdyne (Canoga Park, CA). Acknowledgements are also extended to the late Dr. William J. Arbegast, former Director of NSF Center for Friction Stir Processing (CFSP), for his continuous support and encouragement.

\section{References}

1. C.T. Sims, N.S. Stoloff, W.C. Hagel, Superalloys, (New York, NY: Wiley, 1987), 165-187.

2. R.G. Carlson, and J.F. Radavich, "Microstructure Characterization of Cast 718", Superalloy 718: Metallurgy and Applications, ed. E.A. Loria (Warrendale, PA: The Minerals, Metals and Materials Society, 1989), 79-95.

3. S. Sharma, Z. Ma, R. Mishra, "Effect of Friction Stir Processing on Fatigue Behavior of A356 Alloy," Scripta Materialia, 51 (2004) 237-241.

4. M. Santella, T. Engstrom, D. Storjohann, T. Pan, "Effects of Friction Stir Processing on Mechanical Properties of the Cast Aluminum Alloys A319 and A356," Scripta Materialia, 53 (2005), 201-206.

5. A. Feng, Z. Ma, "Enhanced Mechanical Properties of Mg-Al$\mathrm{Zn}$ Cast Alloy via Friction Stir Processing," Scripta Materialia, 56 (2007), 397-400.

6. P. Cavaliere, P. De Marco, "Fatigue Behaviour of Friction Stir Processed AZ91 Magnesium Alloy Produced by High Pressure Die Casting," Materials Characterization, 58 (2007), 226-232.

7. A. Pilchak, M. Juhas, J. Williams, "Microstructural Changes Due to Friction Stir Processing of Investment-Cast Ti-6Al4V," Metallurgical and Materials Transactions A, 38 (2007), 401-408.

8. B.K. Jasthi, E.Y. Chen, W.J. Arbegast, M. Heringer, D.R. Bice, S.M. Howard, "Friction Stir Processing of Cast Inconel 718," Friction Stir Welding and Processing VI, (2011), 25-32.

9. M. Fuller, S. Swaminathan, A. Zhilyaev, T. McNelley, "Microstructural Transformations and Mechanical Properties of Cast NiAl Bronze: Effects of Fusion Welding and Friction Stir Processing" Materials Science and Engineering: A, 463 (2007), 128-137.

10. Z. Ma, "Friction Stir Processing Technology: A Review," Metallurgical and Materials Transactions A, 39 (2008), 642658.

11. R. Mishra, Z. Ma, I. Charit, "Friction stir processing: a novel technique for fabrication of surface composite," Materials Science and Engineering: A, 341 (2003), 307-310.

12. K. Oh-Ishi, T. McNelley, "Microstructural Modification of As-cast NiAl Bronze by Friction Stir Processing," 
Metallurgical and Materials Transactions A, 35 (2004), 29512961.

13. R. Mishra, M. Mahoney, S. McFadden, N. Mara, A. Mukherjee, "High strain rate superplasticity in a friction stir processed 7075 Al alloy," Scripta Materialia, 42 (2000), 163168.

14. R.S. Mishra, M.W. Mahoney, "Friction stir processing: a new grain refinement technique to achieve high strain rate superplasticity in commercial alloys," Materials Science Forum, 357 (2001), 507-514.

15. Aerospace Materials Specification (AMS) - 5383E Nickel Alloy, Corrosion and Heat-Resistant, Investment Castings $52.5 \mathrm{Ni}-19 \mathrm{Cr}-3.0 \mathrm{Mo}-5.1 \mathrm{Cb}(\mathrm{Nb})-0.90 \mathrm{Ti}-0.60 \mathrm{Al}-18 \mathrm{Fe}$ Vacuum Melted Homogenization and Solution Heat Treated, SAE International, 2007. 